\title{
Stability Enhancement of Small-Scale Power Grid with Renewable Power Sources by Variable Speed Diesel Power Plant*
}

\author{
Rion Takahashi, Atsushi Umemura, Junji Tamura \\ Department of Earth, Energy and Environmental Engineering, Kitami Institute of Technology, Kitami, Japan \\ Email: rtaka@mail.kitami-it.ac.jp
}

How to cite this paper: Takahashi, R., Umemura, A. and Tamura, J. (2020) Stability Enhancement of Small-Scale Power Grid with Renewable Power Sources by Variable Speed Diesel Power Plant. Journal of Power and Energy Engineering, 8, 1-17. https://doi.org/10.4236/jpee.2020.83001

Received: February 10, 2020

Accepted: March 22, 2020

Published: March 25, 2020

Copyright $\odot 2020$ by author(s) and Scientific Research Publishing Inc. This work is licensed under the Creative Commons Attribution International License (CC BY 4.0).

http://creativecommons.org/licenses/by/4.0/

\begin{abstract}
This paper proposes a power control method to improve a stability of a small-scale power grid with renewable energy sources. In an isolated smallscale power grid such as an island, diesel power plant is main power source which has an environmental burden and expensive running cost due to high priced fossil fuel. Thus, expanding installation of the renewable energy sources such as a wind power is strongly desirable. Such fluctuating energy sources, however, harm power quality of the small-scale power grid, and in addition, conventional power plant in the small-scale power grid cannot, in general, stabilize the grid system with such fluctuating power sources. In this study, Variable Speed Doubly-Fed Induction Generator (VS-DFIG) is proposed to be installed at a diesel power plant instead of a conventional Fixed Speed Synchronous Generator (FS-SG), because quick control of a power balance in the small-scale power grid can be achieved by using the inertial energy of VS-DFIG. In addition, utilization of a Battery Energy Storage System (BESS) is also considered to assist cooperatively the VS-DFIG control. As a result of the simulation analysis by using the proposed method, it is verified that frequency fluctuations due to renewable energy source can be effectively reduced by quick power control of the VS-DFIG compared to the conventional FS-SG, and further control ability can be obtained by utilizing BESS. Moreover, the transient stability of a small-scale power grid during a grid fault can also be enhanced.
\end{abstract}

\section{Keywords}

Small-Scale Power Grid, Variable Speed Doubly-Fed Induction Generator (VS-DFIG), Diesel Power Plant, Wind Power, Battery Energy Storage System (BESS)

^This work was supported by JSPS KAKENHI Grant Number JP18K04099. 


\section{Introduction}

Utilization of renewable energy is spreading worldwide, especially energy conversion from solar and wind energy to electric power is most prevalent form for using renewable energy. However, their fluctuating energy output due to unstable weather condition may influence and disturb a stable operation of a power grid. Under such situations, mitigation of fluctuating power by using energy storage system such as battery has been studied [1] [2] [3] [4], but huge capacity is needed for the energy storage system which causes extremely high costs. Meanwhile, a microgrid concept which is an independent power grid in tiny scale is becoming more common. In the microgrid, flexible control of power generation and consumption can be achieved well compared to large-scale power grid, and many demonstration tests with locally capturing energy, e.g., solar, wind and biomass, have been performed [5] [6] [7] [8]. Such microgrid might become one of the distributed power sources.

There are many small islands with residential areas worldwide, and these power grids are almost small scale and independent of large-scale power grid on the main island. In most cases, main electrical sources in such small-scale power grid are supplied from diesel engine power plants. However, such plants have an environmental and cost problem due to an exhaust gas and fuel transportation by the ship. On the other hand, because most of the islands are in abundant wind energy, and therefore an installation of renewable energy, mainly the wind, is quite significant in order to decrease the dependence on fossil fuel. However, because of fluctuating characteristics of renewable energy due to weather condition, power quality of small-scale power grid with renewable energy sources introduced will be deteriorated. Thus, even a small renewable energy source may not be introduced in such situations. Considering such situations, stabilization of fluctuating power in the small-scale power grid is vitally important in order to increase renewable energy utilization.

In order to solve the problems stated above, several kinds of generator systems have been proposed and investigated to control microgrid system with renewable energy sources [9] [10] [11]. Most of these systems are composed of a conventional synchronous generator driven by a diesel engine as the main power source, and energy storage system is often considered. But as mentioned previously, installation of a large storage system is not very realistic because of high cost. If the diesel engine driven generator as a main power source can have an ability of quick control of its power output, then the generator can greatly contribute for stabilizing the fluctuating power. If the conventional fixed speed synchronous generator, however, is adopted in such system, its diesel engine has to perform rapid output control and then the life of the engine will be shortened. In contrast, if the variable speed generator is adopted in such system, the diesel engine does not need to respond so rapidly because of the inertial response of the variable speed generator. Under such consideration, application of variable speed diesel generator has been pro- 
posed in several reports [12] [13] [14]. However, there is little report in which detailed analyses of the small power system including the diesel power plant and wind power station with natural fluctuating wind condition as a renewable energy source are performed with considering their cooperative control system.

In this paper, a new design and operation method of small-scale power grid is proposed in order to improve stability of the system frequency against fluctuating power from the wind power station, in which a variable speed diesel generator with employing Variable Speed Doubly-Fed Induction Generator (VS-DFIG) is adopted and controlled cooperatively with a Battery Energy Storage System (BESS). In this study, a degree of the smoothing effect which is depending on various conditions of the small-scale power grid is investigated by a simulation analysis, and then a possible amount of the wind power installation is estimated for various environmental conditions of the islands. In addition, the simulation analysis includes a case of grid fault and the effect of the proposed system on transient stability enhancement is also evaluated.

Among the similar analyses reported so far, there are reports about microgrids including diesel generators, BESSs and renewable energy sources. For example, several simulation results for transient performance like a step load change obtained by using detailed numerical model are presented in [15]-[26], and analyses for controllability improvement under fluctuating power during long time period are presented in [27] [28] [29] [30] [31] [32]. However there are few reports in which the VS-DFIG is considered. This paper proposes a new strategy to enhance the controllability of the main generator in a small-scale power grid by adopting the VS-DFIG, and thus it will be possible to introduce further renewable energy sources to small-scale power grid with the proposed VS-DFIG based diesel power plant.

The simulation analysis in this paper is performed by PSCAD/EMTDC.

\section{Overview of the Modeling}

\subsection{Model of Small-Scale Power Grid}

Figure 1 shows a construction of the small-scale power system model. A Diesel Generator 1 (DG1) and a Diesel Generator 2 (DG2) are diesel power plants. Squirrel Cage Induction Generator (SCIG) is a constant speed wind generator. Power ratings, rated voltage and impedances of the transmission lines are shown in Figure 1. DG1 is a conventional FS-SG equipped with speed governor and automatic voltage regulator. DG2 has the same rating as DG1 for which, however, two types of generator are used. One is a FS-SG same as DG1 and the other is a VS-DFIG. In this study, difference between the performances of the two types of DG2 for power grid frequency characteristics is evaluated. The wind power station is composed of single SCIG equipped with aerodynamically characterized wind turbine. Load A and B are modeled by using resistive components as consumers. 


\subsection{Model of Diesel Power Plant}

The speed governor model of the diesel power plant shown in Figure 2 is used for DG1 and DG2. Though several types of diesel engine governor models have been reported, a simplified model is used in this study [33] [34]. The speed governor generates the output reference of the engine's torque in order to maintain its speed to be the reference speed by using PID controllers. DG1 governor has an effective integral element, and thus, DG1 operates under Load Frequency Control (LFC) which keeps a power balance between supply and demand on the order of several minutes, while DG2 operates under governor free because its integral controller is not so effective. Each parameter of the governors is shown in Table 1. Parameters of the PID controller $K_{P}, K_{I}, K_{D}$ and $T_{D}$ are determined through a trial and error method in order to obtain the most desirable performance.

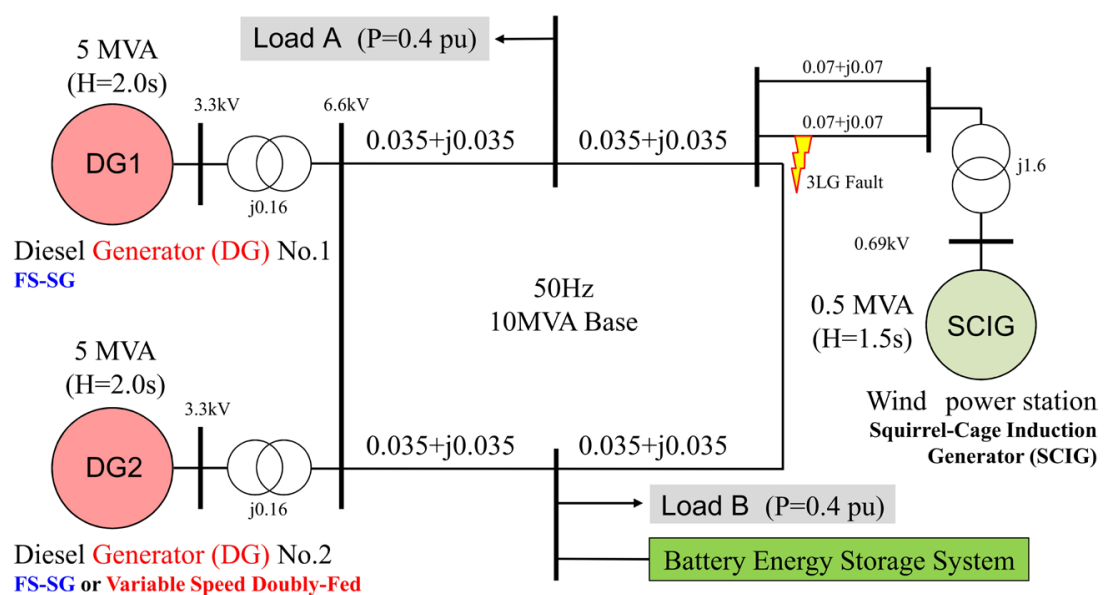

FS-SG or Variable Speed Doubly-Fed

Induction Generator (VS-DFIG)

Figure 1. Model system of small-scale power grid.

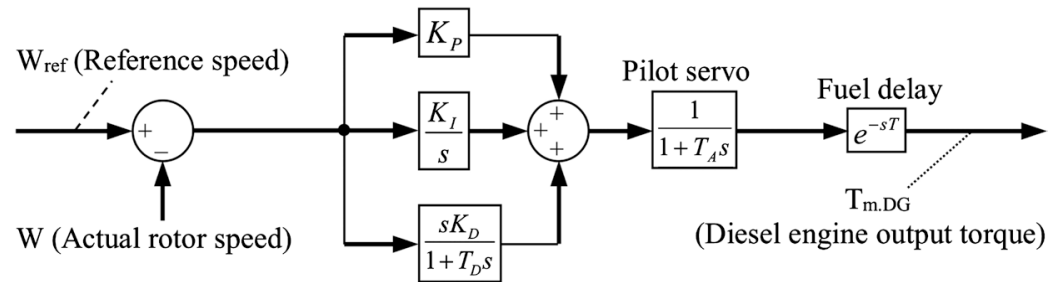

Figure 2. Model of the diesel engine and its speed governor.

Table 1. Parameters of the speed governor of the diesel engines.

\begin{tabular}{cccc}
\hline Parameters & DG1 & DG2 as FS-SG & DG2 as VS-DFIG \\
\hline Proportional gain $\mathrm{K}_{\mathrm{P}}$ & 6.0 & 4.0 & 0.8 \\
Integral gain $\mathrm{K}_{\mathrm{I}}$ & 1.0 & 0.001 & 0.004 \\
Differential gain $\mathrm{K}_{\mathrm{D}}$ & 10.0 & 10.0 & 2.0 \\
Time constant $\mathrm{T}_{\mathrm{D}}$ & 0.1 & 0.1 & 0.1 \\
Time constant of the pilot servo $\mathrm{T}_{\mathrm{A}}$ & 1.0 & 1.0 & 1.0 \\
Time constant of the diesel fuel delay $\mathrm{T}$ & 0.5 & 0.5 & 0.5 \\
\hline
\end{tabular}


Time constant $T_{A}$ and $T$ of the diesel engine model are typical value.

\subsection{Model of FS-SG}

The FS-SG is used widely as a hydraulic, thermal, and diesel power plants. Table 2 shows parameters of the FS-SG for the diesel generators in this study. The automatic voltage regulator shown in Figure 3 is equipped with each FS-SG.

\subsection{Model of VS-DFIG}

A basic configuration of the VS-DFIG and its secondary excitation control system is shown in Figure 4. This system has an advantage that only partial power rating is needed for its electronic power converter. Since the VS-DFIG can control its reactive power according to specified reference, automatic voltage regulator for FS-SG shown in Figure 3 is not used. Active power of the VS-DFIG can

Table 2. Parameters of the FS-SG.

\begin{tabular}{ll}
\hline Rated capacity & $5 \mathrm{MVA}$ \\
Rated voltage & $3.3 \mathrm{kV}$ \\
Resistance of stator winding & 0.0025 p.u. \\
Leakage reactance of stator winding & 0.14 p.u. \\
Resistance of field winding & 0.0004 p.u. \\
Leakage reactance of field winding & 0.2 p.u. \\
D-axis synchronous reactance $\mathrm{X}_{\mathrm{d}}$ & $1.66 \mathrm{p} . \mathrm{u}$. \\
D-axis damper winding resistance $\mathrm{r}_{\mathrm{kd}}$ & 0.0051 p.u. \\
D-axis damper winding leakage reactance $\mathrm{X}_{\mathrm{kd}}$ & 0.0437 p.u. \\
Q-axis synchronous reactance $\mathrm{X}_{\mathrm{q}}$ & $0.91 \mathrm{p} . \mathrm{u}$. \\
Q-axis damper winding resistance $\mathrm{r}_{\mathrm{kq}}$ & 0.0084 p.u. \\
Q-axis damper winding leakage reactance $\mathrm{X}_{\mathrm{kq}}$ & 0.106 p.u. \\
Inertia constant $\mathrm{H}$ & $2.0 \mathrm{~s}$ \\
\hline
\end{tabular}

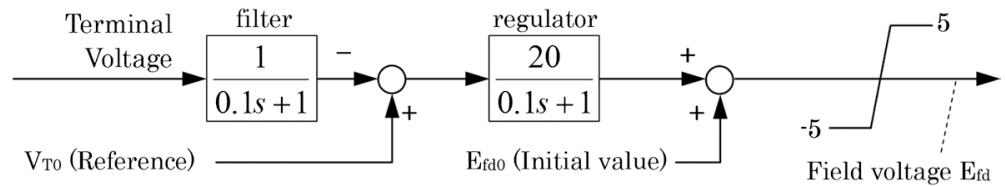

Figure 3. Model of automatic voltage regulator of the FS-SGs.

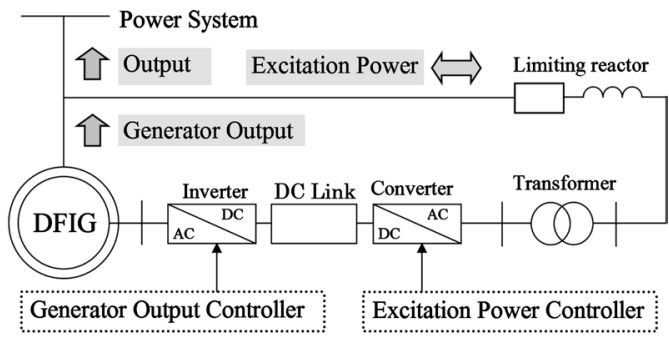

Figure 4. Model of the VS-DFIG and its controller structures. 
be controlled according to power grid frequency as explained below. Table 2 shows parameters of the VS-DFIG. Also, parameters of the SCIG wind generator are also shown in Table 3 because both of VS-DFIG and SCIG are induction machines.

\subsection{Model of BESS}

In this study, a BESS is utilized and installed at Load B in parallel and it is activated temporarily when rapid frequency fluctuation that the VS-DFIG cannot control occurs. The BESS is modeled using an ideal electrical source which has no power losses and is operating in unity power factor at the AC terminal. Reference of the BESS output power is generated as shown in Figure 5. The BESS power control is activated when the frequency deviation is exceeding $\pm 0.075 \mathrm{~Hz}$ and the BESS power is limited to $\pm 125 \mathrm{~kW}$ in this study.

\subsection{Model of Wind Power Station}

The wind power station is modeled as a single wind generator composed of a SCIG and a wind turbine of which aerodynamic characteristics are expressed as following Equations (1)-(4) [35]. The output of the generator is regulated by a pitch angle controller of the wind turbine as shown in Figure 6 when wind

Table 3. Parameters of the induction generators (VS-DFIG and SCIG).

\begin{tabular}{ccc}
\hline Parameters & VS-DFIG & SCIG \\
Rated capacity & $5 \mathrm{MVA}$ & $0.5 \mathrm{MVA}$ \\
Rated voltage & $6.6 \mathrm{kV}$ & $0.69 \mathrm{kV}$ \\
Resistance of stator winding & $0.01 \mathrm{pu}$ & $0.01 \mathrm{pu}$ \\
Leakage reactance of stator winding & $0.15 \mathrm{pu}$ & $0.07 \mathrm{pu}$ \\
Magnetizing reactance & $3.5 \mathrm{pu}$ & $4.1 \mathrm{pu}$ \\
Resistance of rotor winding & $0.01 \mathrm{pu}$ & $0.007 \mathrm{pu}$ \\
Leakage reactance of rotor winding & $0.15 \mathrm{pu}$ & $0.07 \mathrm{pu}$ \\
Inertia constant & $2.0 \mathrm{~s}$ & $1.5 \mathrm{~s}$
\end{tabular}

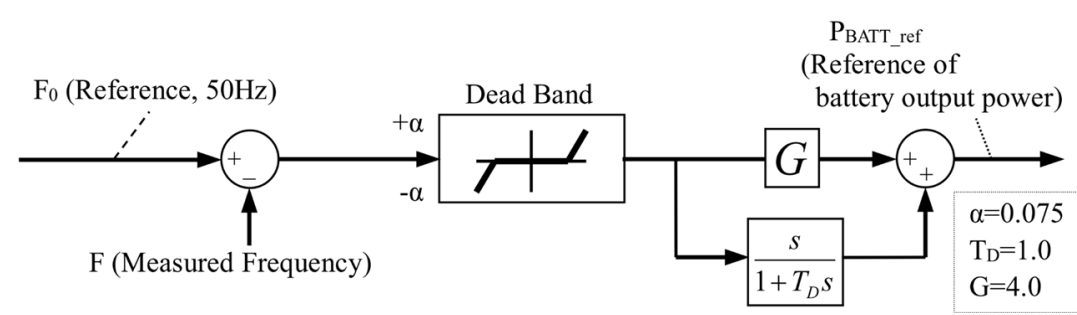

Figure 5. Reference of BESS output.

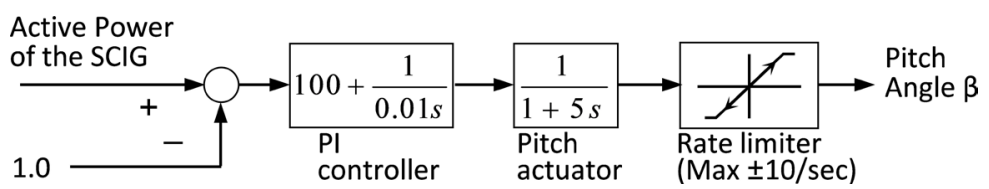

Figure 6. Pitch angle controller of the wind turbine. 
speed is over the rated wind speed.

$$
\begin{gathered}
P_{w t b}=\frac{1}{2} \rho C_{p}(\lambda, \beta) \pi R^{2} V_{w}^{3}[W] \\
C_{P}(\lambda, \beta)=0.5\left(\Gamma-0.022 \beta^{2}-5.6\right) \mathrm{e}^{-0.17 \Gamma} \\
\lambda=\frac{w_{w t b} R}{V_{w}} \\
\Gamma=\frac{R}{\lambda} \cdot \frac{3600}{1609}
\end{gathered}
$$

where $P_{w t b}$ : output of the generator [W]; $\lambda$ : tip speed ratio; $R$ : radius of the wind turbine $[\mathrm{m}] ; \omega_{w t b}$ : speed of the wind turbine $[\mathrm{rad} / \mathrm{s}] ; \rho$ : air density $\left[\mathrm{kg} / \mathrm{m}^{3}\right] ; \beta$ : pitch angle of the wind turbine [deg]; $V_{w}$ : wind speed $[\mathrm{m} / \mathrm{s}]$.

\section{VS-DFIG Output Control System}

In the case that DG2 in Figure 1 is VS-DFIG, VS-DFIG compensates power fluctuations in order to suppress frequency fluctuations of the power grid. The control system is composed of proportional controller and differential controller (inexact differential) as shown in Figure 7 so that relatively quick change of the frequency can be controlled.

\section{Simulation Analysis}

\subsection{Simulation Settings}

Wind speed data used in the simulation analysis are actual wind speed data measured in Hokkaido Island, Japan. This is because it is important to evaluate performance of the proposed variable speed diesel power plant for stabilizing power system frequency fluctuations under natural wind speed condition. Two profiles of wind generator output shown in Figure 8 are used in the simulation analysis and they are referred as Profile No.1 and Profile No.2. The wind speed data for Profile No.1 and Profile No.2 are for 30 minutes with 1 second sampling, and resulting wind generator outputs have almost same average value but different fluctuating level (standard deviation) to each other as shown in Figure 8. Simulation analyses for 3 cases have been performed for the combination of two diesel generators; i.e., DG1 and DG2 are both conventional synchronous generator (Case 1), DG2 is the proposed VS-DFIG (Case 2), and the BESS is added to Case 2 (Case 3).

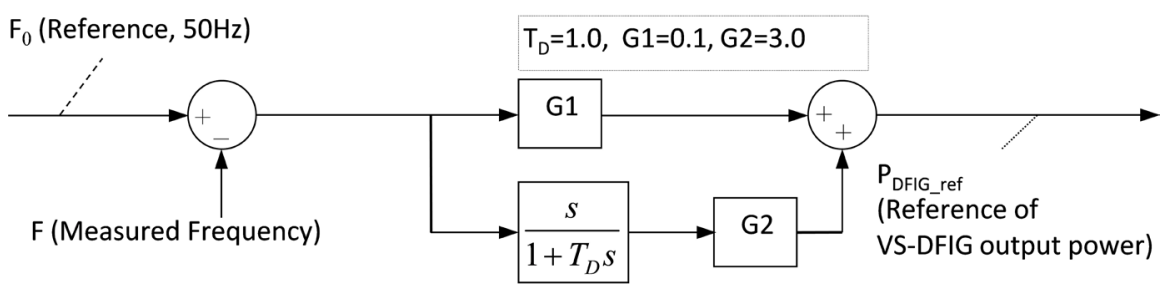

Figure 7. VS-DFIG output control system for stabilization of the small-scale power grid. 


\subsection{Simulation Result 1-Compensation of Power Fluctuation under Natural Wind Condition}

Table 4 and Figure 9 show the calculated standard deviations of the system frequency in the three cases under the 2 wind generator output profiles. It can be seen the frequency fluctuation can be controlled in the latter two cases (Case 2 and Case 3) much better than the first case (Case 1).

In addition, maximum and minimum deviations of the system frequency from the synchronous frequency $(50 \mathrm{~Hz})$ are shown in Table 5 and Figure 10. It is also

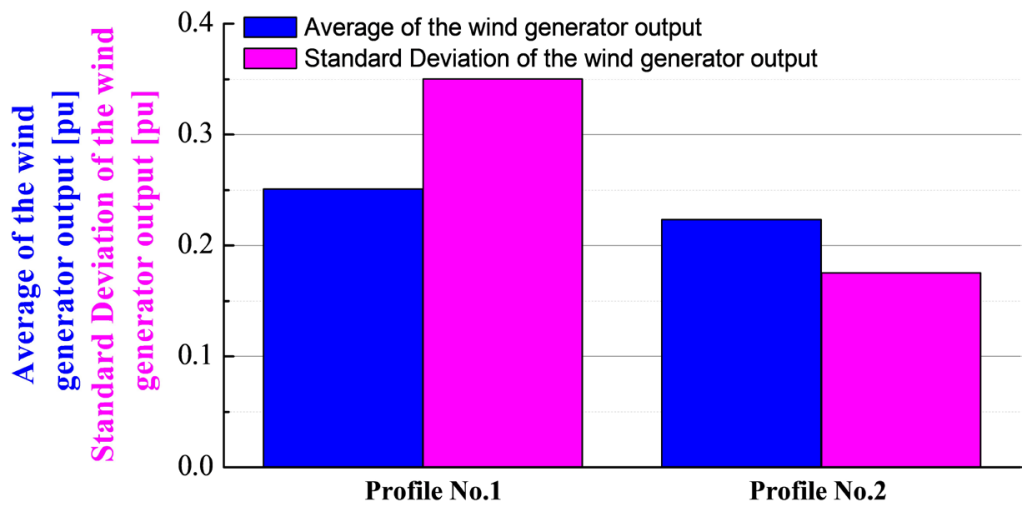

Figure 8. Output power profile of the wind power station.

Table 4. Standard deviation of the grid frequency fluctuation.

\begin{tabular}{cccc}
\hline Profile No. & $\begin{array}{c}\text { Case 1 } \\
\text { FS-SG as DG2 }\end{array}$ & $\begin{array}{c}\text { Case 2 } \\
\text { VS-DFIG as DG2 }\end{array}$ & $\begin{array}{c}\text { Case 3 } \\
\text { VS-DFIG as DG2 with BESS }\end{array}$ \\
\hline 1 & 0.082 & 0.063 & 0.047 \\
2 & 0.065 & 0.054 & 0.043 \\
\hline
\end{tabular}

DG1 is FS-SG in all cases. Unit is in Hz.

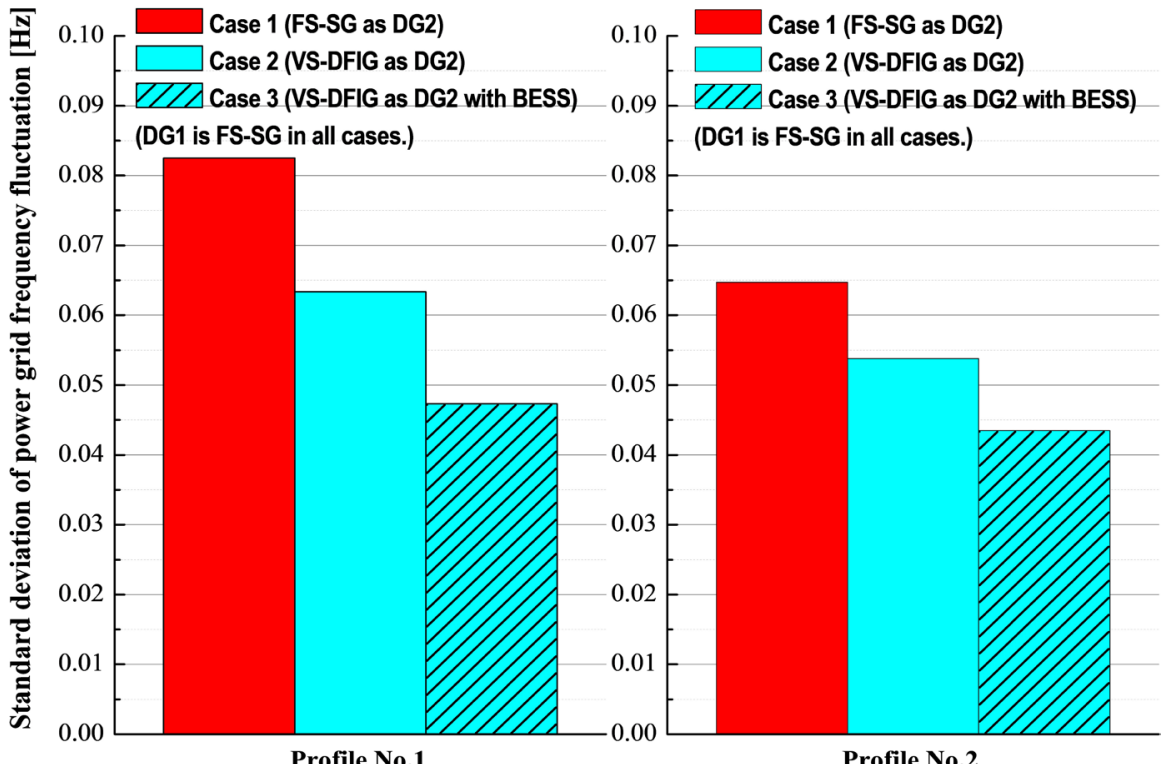

Figure 9. Standard deviation of grid frequency fluctuation. 
Table 5. Maximum deviation of the grid frequency.

\begin{tabular}{ccccccc}
\hline \multirow{2}{*}{ Profile No. } & \multicolumn{2}{c}{ Case 1 } & \multicolumn{2}{c}{ Case 2 } & \multicolumn{2}{c}{ Case 3 } \\
& \multicolumn{2}{c}{ FS-SG as DG2 } & \multicolumn{2}{c}{ VS-DFIG as DG2 } & \multicolumn{2}{c}{ VS-DFIG as DG2 with BESS } \\
\cline { 2 - 7 } & Increase & Decrease & Increase & Decrease & Increase & Decrease \\
\hline 1 & 0.662 & -0.439 & 0.248 & -0.178 & 0.130 & -0.113 \\
2 & 0.374 & -0.294 & 0.156 & -0.308 & 0.105 & -0.188 \\
\hline
\end{tabular}

DG1 is FS-SG in all cases. Unit is in Hz.

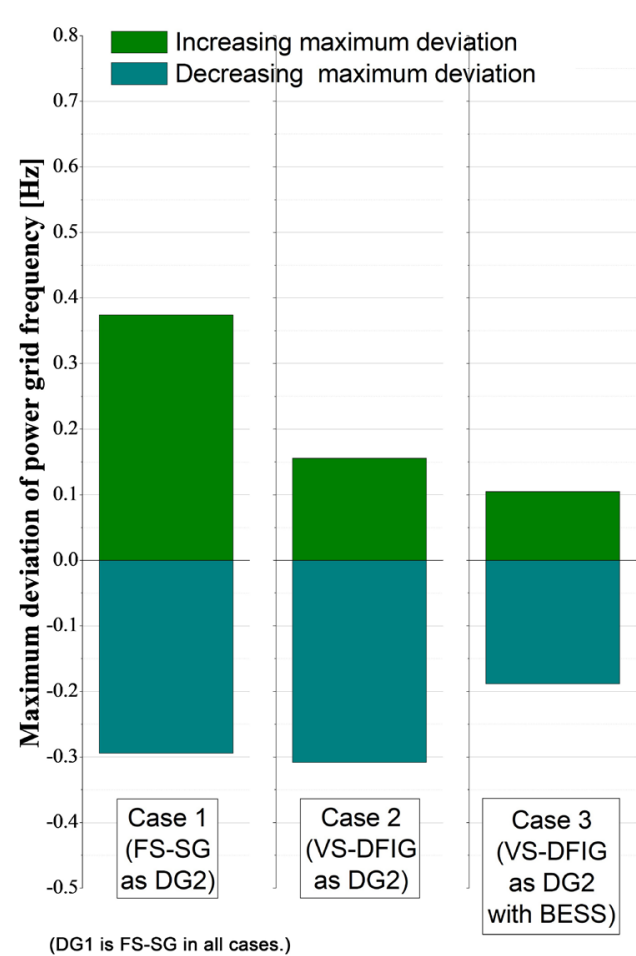

Profile No.1

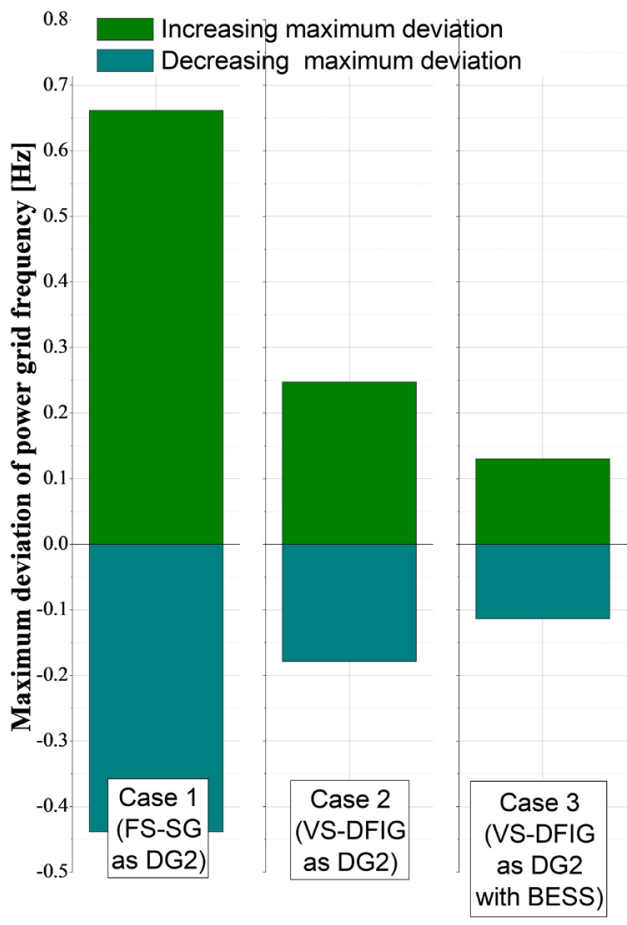

Profile No.2

Figure 10. Maximum deviation of the grid frequency.

seen that the maximum and minimum deviations of the system frequency can also be controlled in Case 2 and Case 3 much better than Case 1.

Though the proposed VS-DFIG can provide the significant contribution to the frequency control, the Battery Energy Storage System (BESS) assistance can provide further improvement. When the power system frequency deviation exceeds $\pm 0.075 \mathrm{~Hz}$ (it is the preset threshold in this study), then the BESS is activated to control its output according to Figure 6. It is clear from Table 4 and Table 5, and Figure 9 and Figure 10 that the BESS control system shown in Figure 5 has sufficient ability in assisting the VS-DFIG to suppress the system frequency fluctuations.

Figure 11 shows time-domain responses (enlarged graphs for 10 minutes including the parts with large fluctuations) of the 3 cases under Profile No.1. As a result, the VS-DFIG can suppress effectively the frequency fluctuations compared to the case of the conventional synchronous generator while the oscillations of its prime mover torque are relatively large. When power compensation by the BESS 

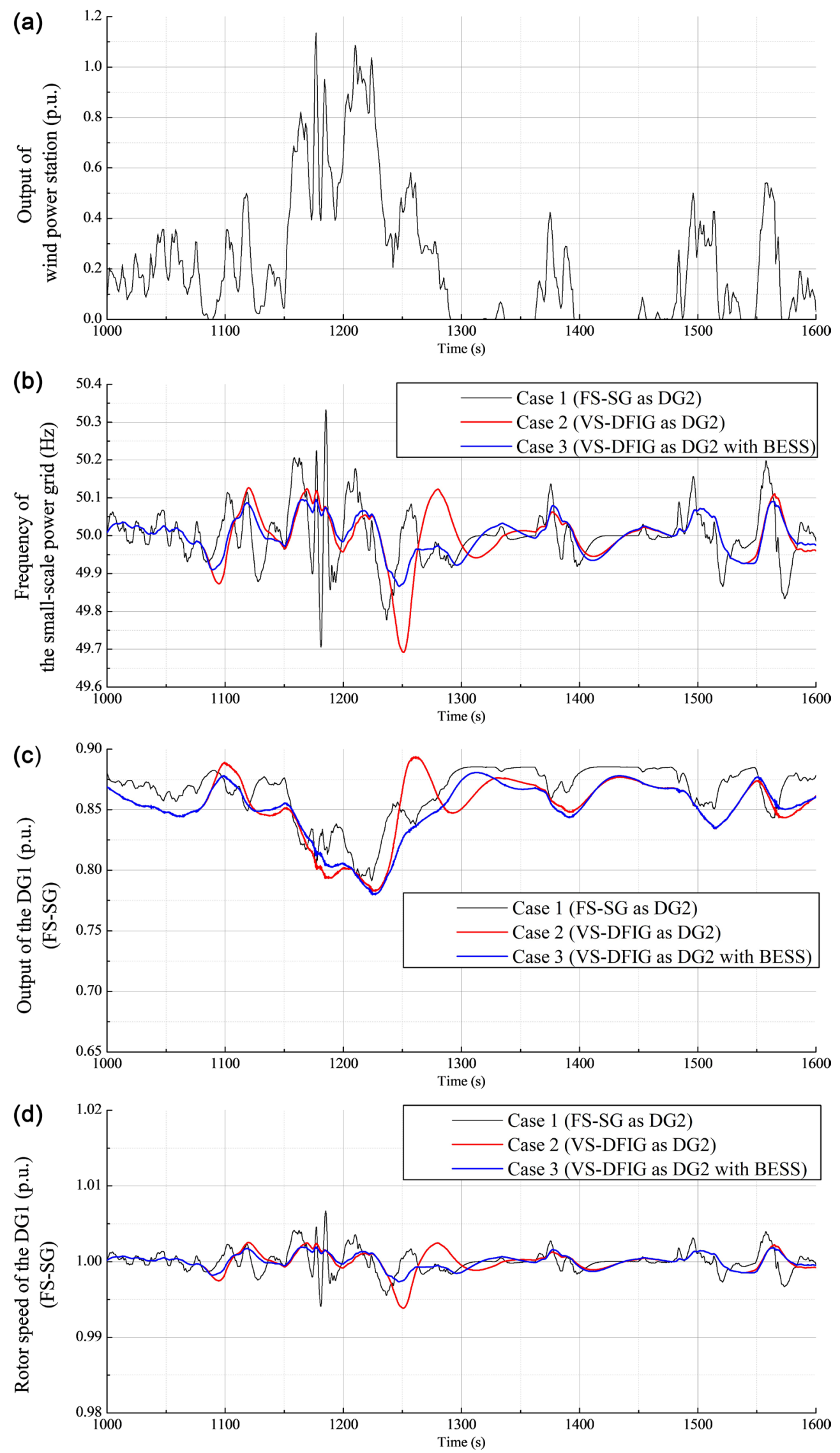

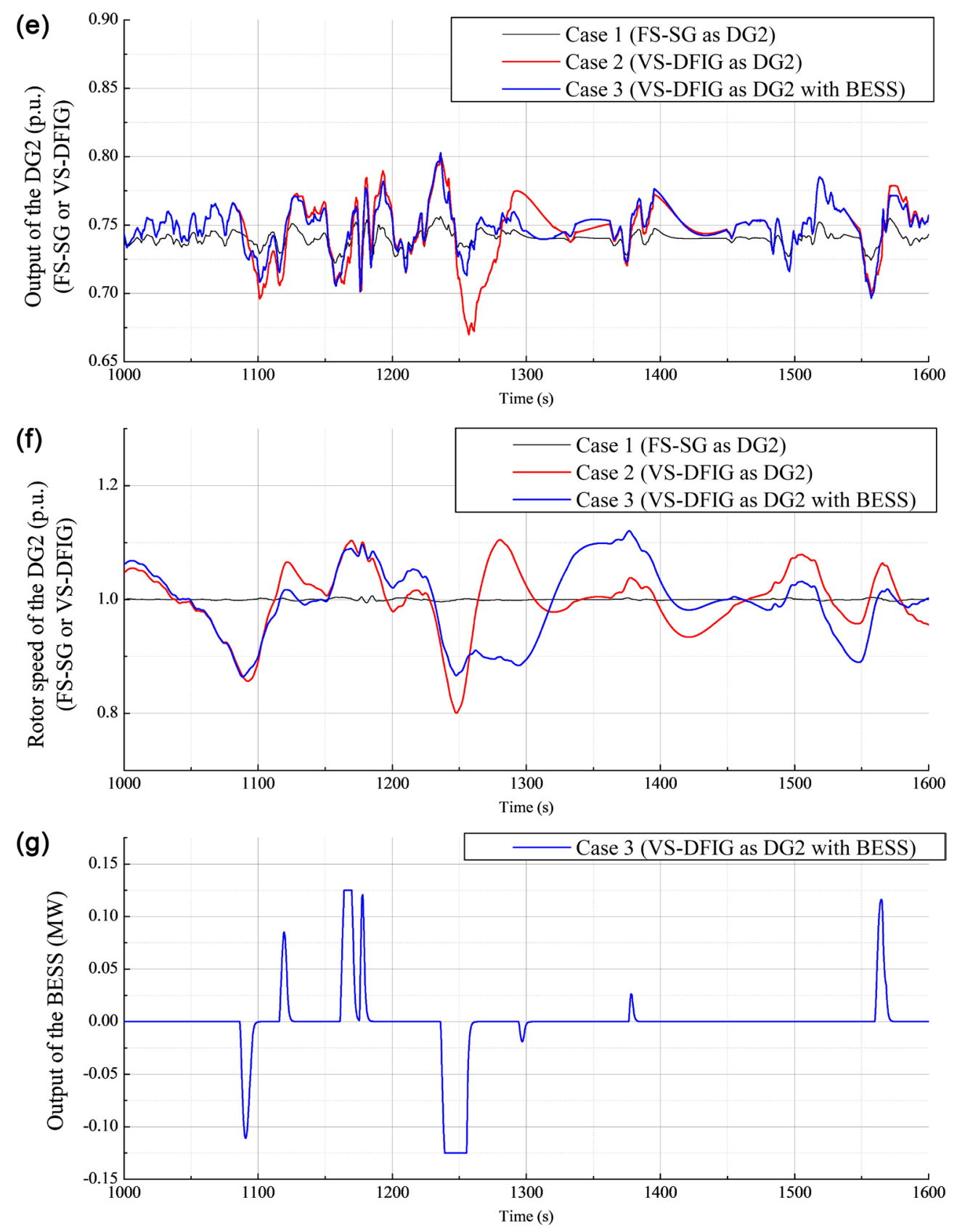

(DG1 is FS-SG in all cases.)

Figure 11. Responses of the power grid for 3 cases under Profile No.1. (a) Output of the wind power station. (b) Frequency of the small-scale power grid. (c) Output of the DG1 (FS-SG). (d) Rotor speed of the DG1 (FS-SG). (e) Output of the DG2 (FS-SG or VS-DFIG). (f) Rotor speed of the DG2 (FS-SG or VS-DFIG). (g) Output of the BESS.

is added, however, the torque oscillations as well as the system frequency fluctuations can be controlled effectively.

\subsection{Simulation Result 2-Transient Stability Enhancement under a Fault Condition at the Grid}

Responses of the grid when a three-phase grounded fault (3LG) was occurred at 

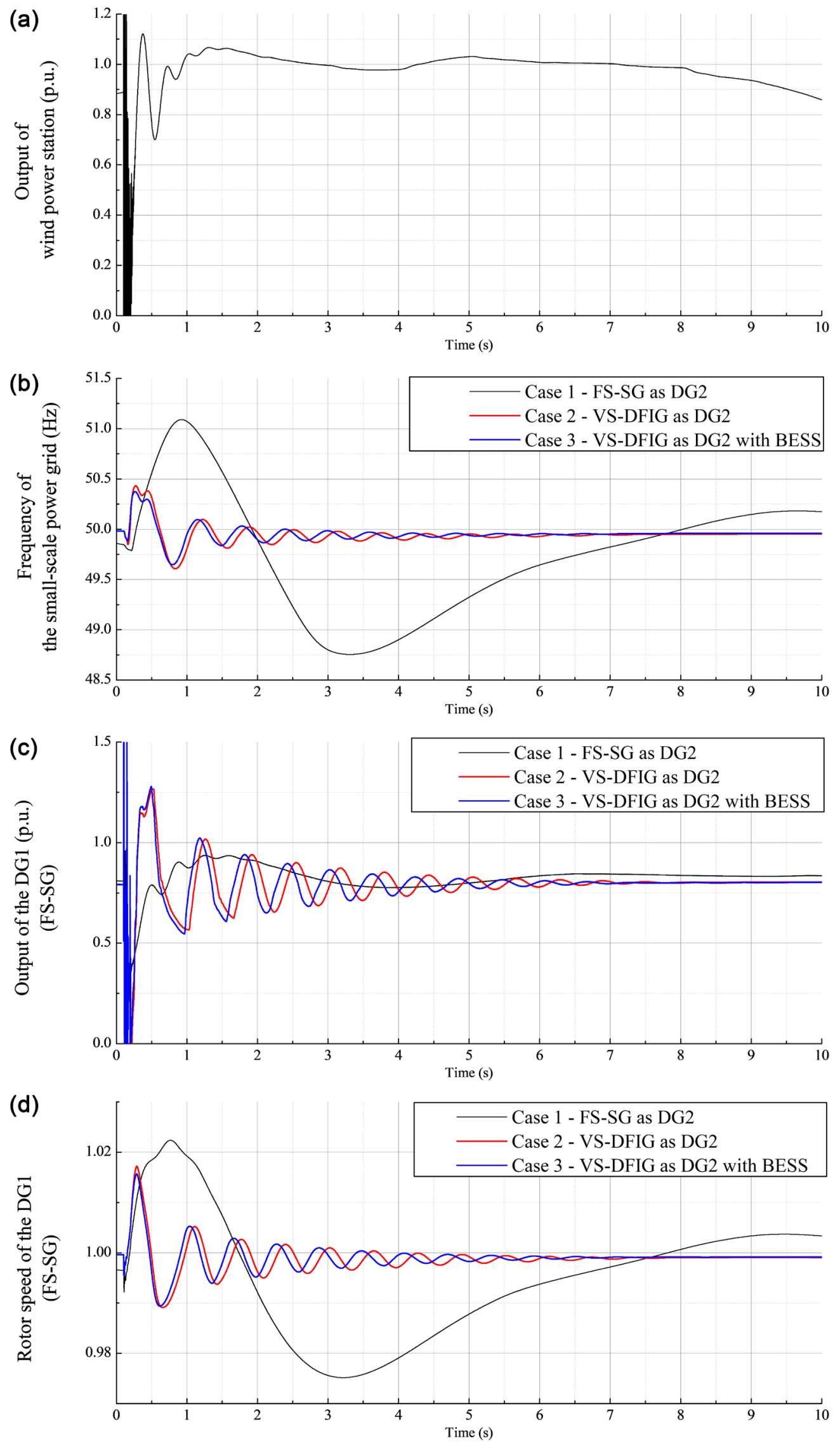

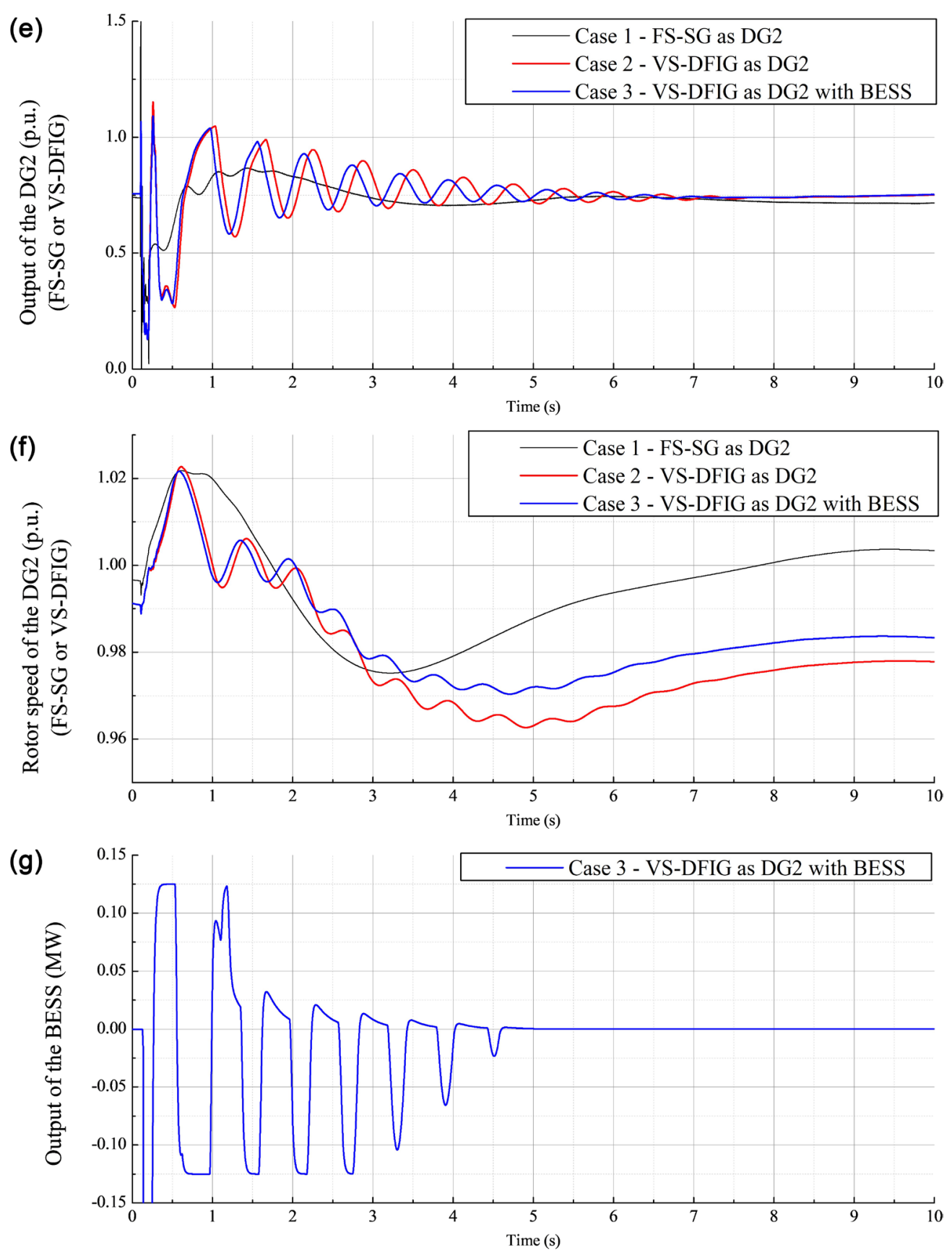

(DG1 is FS-SG in all cases.)

Figure 12. Responses of the power grid for 3 cases under grid fault. (a) Output of the wind power station. (b) Frequency of the small-scale power grid. (c) Output of the DG1 (FS-SG). (d) Rotor speed of the DG1 (FS-SG). (e) Output of the DG2 (FS-SG or VS-DFIG). (f) Rotor speed of the DG2 (FS-SG or VS-DFIG). (g) Output of the BESS.

the point shown in Figure 1 are simulated. Figure 12 shows time-domain responses under $3 \mathrm{LG}$ grid fault. In the case of grid fault, the system frequency fluctuates rapidly and widely due to loss of a power balance. As shown in Figure 12(b), the system frequency varies greatly in the case that DG1 and DG2 are both FS-SG. In contrast, in the case that DG2 is VS-DFIG, this generator regu- 
lates quickly its power and then the frequency fluctuations can be suppressed effectively. Moreover, the BESS can also contribute to stabilize the frequency fluctuations. As a result, it is concluded that the proposed power control by VS-DFIG of the small-scale power grid is also greatly effective for a large disturbance in the grid.

\section{Conclusions}

In this paper, the variable speed diesel generator is proposed to control the grid frequency fluctuations of a small-scale power grid and its performance is evaluated through simulation analyses. In addition to the variable speed diesel generator, BESS is also proposed to assist the frequency control of the variable speed diesel generator.

It is shown from the simulation results that the proposed variable speed diesel generator can control the frequency fluctuations of a small-scale power grid effectively, and further control ability can be obtained by introducing the BESS assistance. Therefore, it can be concluded that wind power installation in an isolated small-scale power grid like a small island can be increased by introducing the proposed cooperative control of VS-DFIG based variable speed diesel power plant and BESS.

Though the proposed system can contribute to increase wind power installation into a small-scale power grid as mentioned above, there are some issues to enhance the performance of the proposed system. For example, stability of the system frequency of a small-scale power grid is depending on parameters of controllers of the VS-DFIG and BESS. There is a possibility for these parameters to be improved more. In addition, the performance of the system against other wind and grid system conditions should be analyzed in order for the system to be effective in any of the conditions. Further improvement of the control systems is undergoing in order to maximize the penetration level of the renewable energy sources into a small-scale power grid which has various types of grid construction and various types of wind and load conditions.

\section{Conflicts of Interest}

The authors declare no conflicts of interest regarding the publication of this paper.

\section{References}

[1] Thomas, F., James, P., Su, D.W., Sean, H. and Francesca, I. (2018) On-Grid Batteries for Large-Scale Energy Storage: Challenges and Opportunities for Policy and Technology. MRS Energy \& Sustainability: A Review Journal, 5, E11.

[2] Zheng, Y.Y., Bryan, J., Kurt, K. and Chresten, T. (2018) Optimization under Uncertainty of a Biomass-Integrated Renewable Energy Microgrid with Energy Storage. Renewable Energy, 123, 204-217. https://doi.org/10.1016/j.renene.2018.01.120

[3] Daniel, A., Juri, B. and Yoash, L. (2017) Battery Storage Technologies for Electrical Applications: Impact in Stand-Alone Photovoltaic Systems. Energies, 10, 1-39. 
https://doi.org/10.3390/en10111760

[4] Mustafa, K., Ceyhun, C., Mehmet, G., Doruk, G., Mehmet, C., Bora, A. and Ahmet, O. (2019) Assessment of Battery Storage Technologies for a Turkish Power Network. Sustainability, 11, 3669. https://doi.org/10.3390/su11133669

[5] Martin, W. (2020) Unpacking the Complexity of Community Microgrids: A Review of Institutions' Roles for Development of Microgrids. Renewable and Sustainable Energy Reviews, 121, Article ID: 109690. https://doi.org/10.1016/j.rser.2019.109690

[6] Nithiyananthan, K. (2019) Microgrid. Intech Open, Research Trends and Challenges in Smart Grids.

[7] Fahad, Z.M., Mohamed, B., Elhoussin, E., Muyeen, S.M., Kuaanan, T. and Josep, G. (2020) Microgrid Transactive Energy: Review, Architectures, Distributed Ledger Technologies, and Market Analysis. IEEE Access, 8, 19410-19432.

https://doi.org/10.1109/ACCESS.2020.2968402

[8] Liu, C.Y. (2019) A Review of Microgrid Development and Technology. IOP Conference Series: Earth and Environmental Science, 300, Article ID: 042048. https://doi.org/10.1088/1755-1315/300/4/042048

[9] Salazar, J., Tadeo, F. and Prada. C. (2015) Modelling of Diesel Generator Sets That Assist Off-Grid Renewable Energy Microgrids. Journal of Renewable Energy and Sustainable Development, 1, 72-80.

[10] Torres, M. and Lopes, L. (2013) Inverter-Based Diesel Generator Emulator for the Study of Frequency Variations in a Laboratory-Scale Autonomous Power System. Energy and Power Engineering, 5, 274-283. https://doi.org/10.4236/epe.2013.53027

[11] Chen, W.Q., Bazzi, A.M., Hare, J. and Gupta, S. (2016) Real-Time Integrated Model of a Micro-Grid with Distributed Clean Energy Generators and Their Power Electronics. 2016 IEEE Applied Power Electronics Conference and Exposition, Long Beach, CA, 20-24 March 2016. https://doi.org/10.1109/APEC.2016.7468240

[12] Waris, T. and Nayar, C.V. (2008) Variable Speed Constant Frequency Diesel Power Conversion System Using Doubly Fed Induction Generator (DFIG). 2008 IEEE Power Electronics Specialists Conference, Rhodes, Greece, 15-19 June 2008. https://doi.org/10.1109/PESC.2008.4592357

[13] Zhou, Z.B., Camara, M.B. and Dakyo, B. (2017) Coordinated Power Control of Variable-Speed Diesel Generators and Lithium-Battery on a Hybrid Electric Boat. IEEE Transactions on Vehicular Technology, 66, 5775-5784. https://doi.org/10.1109/TVT.2016.2638878

[14] Leuchter, J., Rerucha, V., Krupka, Z. and Bauer, P. (2007) Dynamic Behavior of Mobile Generator Set with Variable Speed and Diesel Engine. 2007 IEEE Power Electronics Specialists Conference, Orlando, FL, 17-21 June 2007. https://doi.org/10.1109/PESC.2007.4342366

[15] Chae, W.-K., Lee, H.-J., Hwang, S.-W., Song, I.-K. and Kim, J.-E. (2014) Isolated Micro Grid's Voltage and Frequency Characteristic with Induction Generator Based Wind Turbine. Smart Grid and Renewable Energy, 5, 180-192. https://doi.org/10.4236/sgre.2014.57017

[16] Moradian, M., Tabatabaei, F.M. and Moradian, S. (2013) Modeling, Control \& Fault Management of Microgrids. Smart Grid and Renewable Energy, 4, 99-112.

https://doi.org/10.4236/sgre.2013.41013

[17] Worku, M.Y., Hassan, M.A. and Abido, M.A. (2019) Real Time Energy Management and Control of Renewable Energy Based Microgrid in Grid Connected and Island Modes. Energies, 12, 276. https://doi.org/10.3390/en12020276 
[18] Moon, H.-J., Kim, Y.J. and Chang, J.W. (2019) Decentralised Active Power Control Strategy for Real-Time Power Balance in an Isolated Microgrid with an Energy Storage System and Diesel Generators. Energies, 12, 151. https://doi.org/10.3390/en12030511

[19] Oureilidis, K.O., Bakirtzis, E.A. and Demoulias, C.S. (2016) Frequency-Based Control of Islanded Microgrid with Renewable Energy Sources and Energy Storage. Journal of Modern Power Systems and Clean Energy, 4, 54-62. https://doi.org/10.1007/s40565-015-0178-z

[20] Chen, L.J., Wang, Y.Y., Zheng, T.W. and Zhen, Q.S. (2017) Consensus-Based Distributed Control with Communication Time Delays for Virtual Synchronous Generators in Isolate Microgrid. Energy and Power Engineering, 9, 102-111. https://doi.org/10.4236/epe.2017.94B013

[21] Su, J.J., Zheng, J.Y., Cui, D.M., Li, X.B., Hu, Z.J. and Zhang, C.X. (2013) An Integrated Control Strategy Adopting Droop Control with Virtual Inductance in Microgrid. Engineering, 5, 44-49. https://doi.org/10.4236/eng.2013.51B008

[22] Mishra, S., Sharma, R. and Sharma, D. (2015) Coordinated Active Power Control of Wind, Solar and Diesel Generator in a Microgrid. IFAC-Papers 48-30, 7-12. https://doi.org/10.1016/j.ifacol.2015.12.345

[23] Semshchikov, E., Hamilton, J., Wu, L., Negnevitsky, M., Wang, X. and Lyden, S. (2019) Frequency Control within High Renewable Penetration Hybrid Systems Adopting Low Load Diesel Methodologies. Energy Procedia, 160, 483-490. https://doi.org/10.1016/j.egypro.2019.02.196

[24] El-Bidairi, K.S., Nguyen, H.D., Mahmoud, T.S., Jayasinghe, S.D.G. and Guerrero, J.M. (2020) Optimal Sizing of Battery Energy Storage Systems for Dynamic Frequency Control in an Islanded Microgrid: A Case Study of Flinders Island, Australia. Energy, 195, Article ID: 117059. https://doi.org/10.1016/j.energy.2020.117059

[25] Armghan, H., Yang, M., Armghan, A., Ali, N., Wang, M.Q. and Ahmad, I. (2020) Design of Integral Terminal Sliding Mode Controller for the Hybrid AC/DC Microgrids Involving Renewables and Energy Storage Systems. Electrical Power and Energy Systems, 119, Article ID: 105857.

https://doi.org/10.1016/j.ijepes.2020.105857

[26] Abazari, A., Monsef, H. and Wu, B. (2019) Coordination Strategies of Distributed Energy Resources Including FESS, DEG, FC and WTG in Load Frequency Control (LFC) Scheme of Hybrid Isolated Micro-Grid. Electrical Power and Energy Systems, 109, 535-547. https://doi.org/10.1016/j.ijepes.2019.02.029

[27] Zhao, H.R., Wu, Q.W., Wang, C.S., Cheng, L. and Rasmussen, C.N. (2015) Fuzzy Logic Based Coordinated Control of Battery Energy Storage System and Dispatchable Distributed Generation for Microgrid. Journal of Modern Power Systems and Clean Energy, 3, 422-428. https://doi.org/10.1007/s40565-015-0119-x

[28] Qi, X., Bai, Y., Luo, H.H., Zhang, Y.Q., Zhou, G.P. and Wei, Z.H. (2018) Novel Distributed Optimal Control of Battery Energy Storage System in an Islanded Microgrid with Fast Frequency Recovery. Energies, 11, 1955. https://doi.org/10.3390/en11081955

[29] Wang, C.S., Li, J.M. and Hu, Y.K. (2019) Frequency Control of Isolated Wind-Diesel Microgrid Power System by Double Equivalent-Input-Disturbance Controllers. IEEE Access, 7, 105617-105626.

https://doi.org/10.1109/ACCESS.2019.2932472

[30] Kerdphol, T., Watanabe, M., Hongesombut, K. and Mitani, Y. (2019) Self-Adaptive Virtual Inertia Control-Based Fuzzy Logic to Improve Frequency Stability of Microgrid 
with High Renewable Penetration. IEEE Access, 7, 76071-76083. https://doi.org/10.1109/ACCESS.2019.2920886

[31] Ali, H., Magdy, G., Li, B.B., Shabib, G., Elbaset, A.A., Xu, D.G. and Mitani, Y. (2019) A New Frequency Control Strategy in an Islanded Microgrid Using Virtual Inertia Control-Based Coefficient Diagram Method. IEEE Access, 7, 16979-16990. https://doi.org/10.1109/ACCESS.2019.2894840

[32] Kerdphol, T., Rahman, F.S., Watanabe, M., Mitani, Y., Turschner, D. and Beck, H.-P. (2019) Enhanced Virtual Inertia Control Based on Derivative Technique to Emulate Simultaneous Inertia and Damping Properties for Microgrid Frequency Regulation. IEEE Access, 7, 14422-14433. https://doi.org/10.1109/ACCESS.2019.2892747

[33] Roy, S., Malik O.P. and Hope, G.S. (1993) A k-Step Predictive Scheme for Speed Control of Diesel Driven Power Plants. IEEE Transactions on Industry Applications, 29, 389-396. https://doi.org/10.1109/28.216549

[34] Ahmad, A. and Siddiqui, A.S. (2014) Modeling of a Wind Diesel Integrated System with No Storage. International Journal of Emerging Technology and Advanced Engineering, 4, 106-112.

[35] Wasynczuk, O., Man, D.T. and Sullivan, J.P. (1981) Dynamic Behavior of a Class of Wind Turbine Generators during Random Wind Fluctuations. IEEE Transactions on Power Apparatus and Systems, PAS-100, 2837-2854.

https://doi.org/10.1109/TPAS.1981.316400 